\title{
Tribological Behavior Simulation of Ceramic Material Using the Finite Element Analysis
}

\author{
ADINA OANA ARMENCIA, LOREDANA LILIANA HURJUI, \\ CRISTINA CLAUDIA TARNICERIU, IULIA SAVEANU*, CARINA BALCOS \\ University of Medicine and Pharmacy Gr.T.Popa, Faculty of Dental Medicine, 16 Universitatii Str., 700115, Iasi, Romania
}

Abstract: Simulating the biomechanical behavior of a reconstruction using the finite element analysis method is a modern method necessary before the practical stage of a research, thus enabling the precise shaping of certain trajectories in the approach of certain directions of practical applicability, as well as obtaining final results with relevant data (results coupled with experimental models that reiterate the clinical situation that will be later analyzed).

Keywords: tribological behavior, simulation, dental structures, restorative materials

\section{Introduction}

Our study aimed to analyze, using the finite element method, the state of stress and strain recorded at the point of direct contact between two structures (two hard dental structures in tripod relation), and determine the points of their maximum wear.

\section{Material and method}

In order to determine the state of tension and estimate the areas of maximum wear between the two structures in direct contact, we used a group of 10 patients that needed dental prosthetics.

A tridimensional analysis of the clinical situation was carried out, where the lower molar establishes a tripod contact with its natural antagonist tooth (Figure 1).

The accuracy of the reconstruction is presented in Figure 1 by the precision of the structures represented and analyzed using a CT scan (Figure 2, Figure 3) in one of our patients that needed a ceramic prosthetic. A simple radiography would not have revealed an image as accurate of the aimed structures.
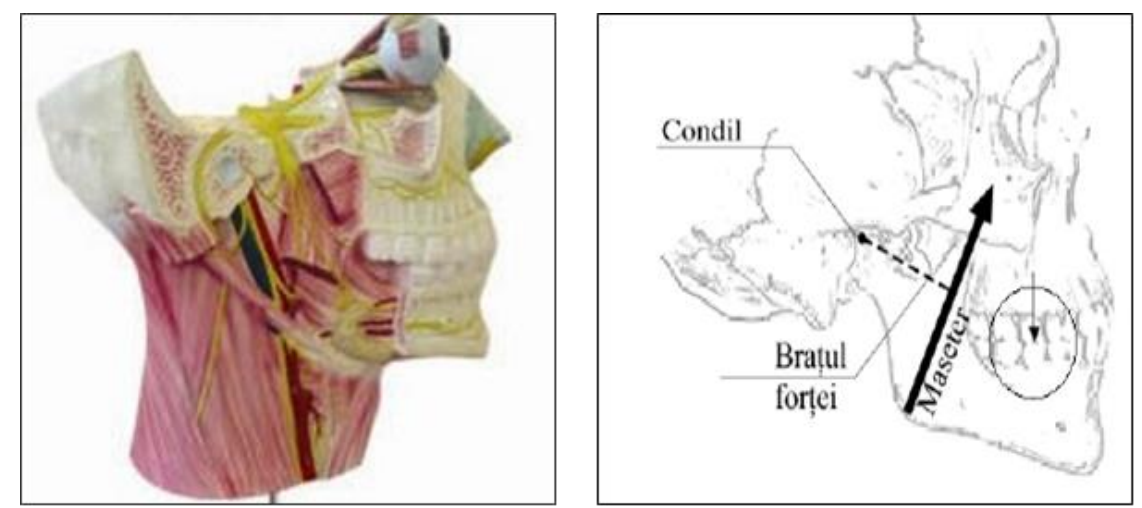

Figure 1. Anatomical reference points used in the $3 \mathrm{D}$ reconstruction

The CT-scan is a diagnosis method that uses special X-ray equipment (the CT scanner) to obtain transverse sections of the scanned object, by means of X-ray detectors. For the 3D reconstruction we used the ABAQUS STANDARD 6.5-1 software.

*email:cisaveanu@prevod.umfiasi.ro,daniulia05@yahoo.com 


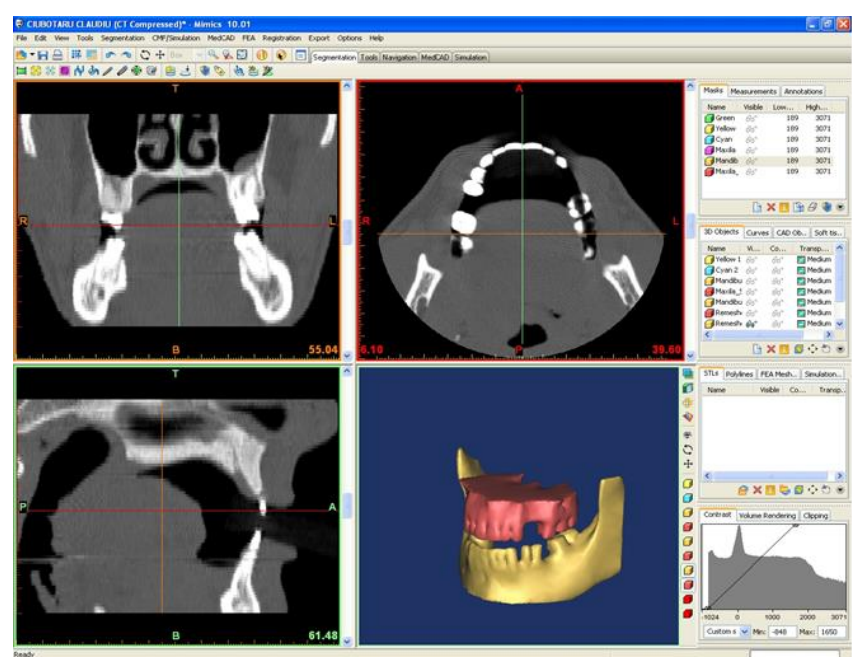

Figure 2. The 3D reconstruction using the CT scan

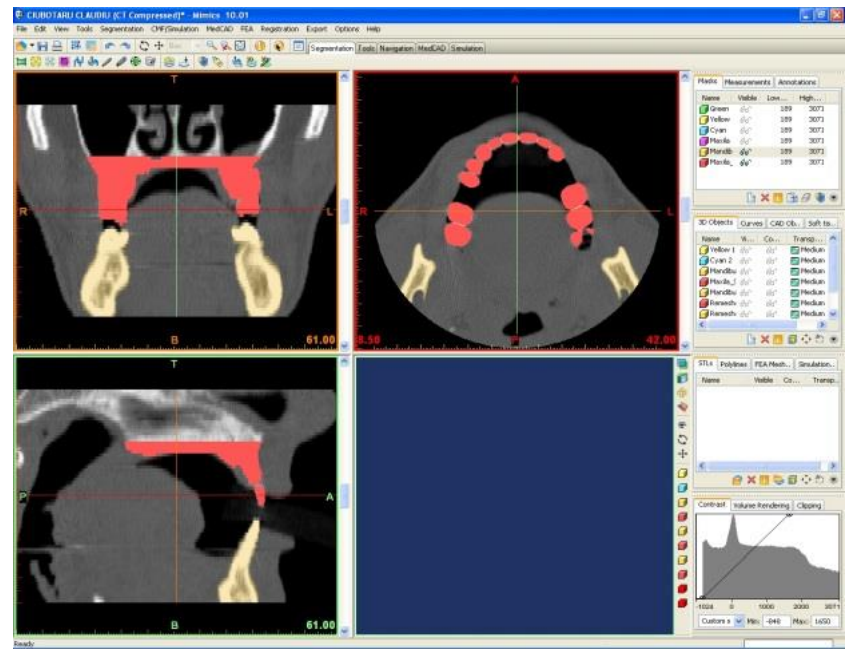

Figure 3. 3D reconstruction of the anatomical reference point in the analyzed CT scan

We considered the muscle forces acting on the mandible in complete occlusion (this forces developed by the masseter, temporal, pterygoid muscles, etc.), whose direction, orientation and size is calculated from the equilibrium condition of temporo-mandibular joint lever $[2,3]$.

The measurements were carried out applying relatively large forces, but considered normal for the oral cavity, of $300 \mathrm{~N}(30 \mathrm{KgF})$ and $500 \mathrm{~N}(50 \mathrm{Kgf})$ and a force of $800 \mathrm{~N}$ considered an overload $(80$ Kgf); testing began with a $300 \mathrm{~N}$ force applied on the crown of the tooth to avoid convergence issues (possible mathematical errors), then the intensity of the force was increased to values high enough to simulate a parafunctional activity. $500 \mathrm{~N}$ is regarded as the average force between the upper physiological limit for which changes are physiological and reversible.

The force that was applied to the mandible bone had an anterior-posterior direction and was oriented at $15^{\circ}$ to the vertical plane. Also, we used embedding into the upper jaw bone to determine the propping of the structure. Due to the fact that during mastication only the lower jaw is mobile, the upper jaw is considered a fixed reference point, so bearings (motion constraints) will only apply to the upper jaw bone and pressure (an evenly distributed force that replaces the mastication muscles' action) will apply on the mandible $[1,5,7]$. 
For measurements, the following factors were taken into account: material properties, namely, modulus of elasticity E and Poisson coefficient corresponding to dental structures, bone, muscle and ceramic material to be used in restoration (Table 1).

Table 1. Material constants used in determinations

\begin{tabular}{|c|c|c|}
\hline COMPONENT & ELASTICITY MODULE [GPa] & POISSON COEFICIENT \\
\hline Bone & 138 & 0.33 \\
\hline Tooth & 186 & 0.31 \\
\hline Muscle & 0.02 & 0.40 \\
\hline Ceramic material & 63 & 0.25 \\
\hline
\end{tabular}

\section{Results and discussions}

When the load reaches about $500 \mathrm{~N}$, the wear area is located throughout the entire area of the mandibular lingual cusps (cuspid, intercuspid groove, distal and middle fossa), the voltage reaching values up to $200 \mathrm{MPa}$ (Figure 4).

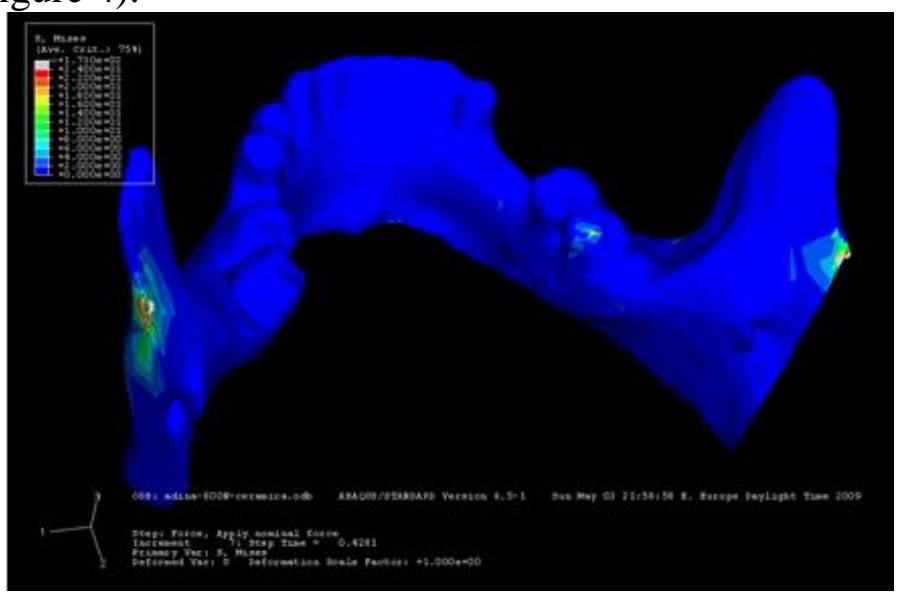

Figure 4. Ceramic molar Von Misses tension for a $300 \mathrm{~N}$ load

The wear surface comprises the middle and oral half of the dental crown (220 MPa), with cervical enlargement $(160 \mathrm{MPa})$, but with minimal impairment of the lingual slope of the edentulous ridge (Figure 5).

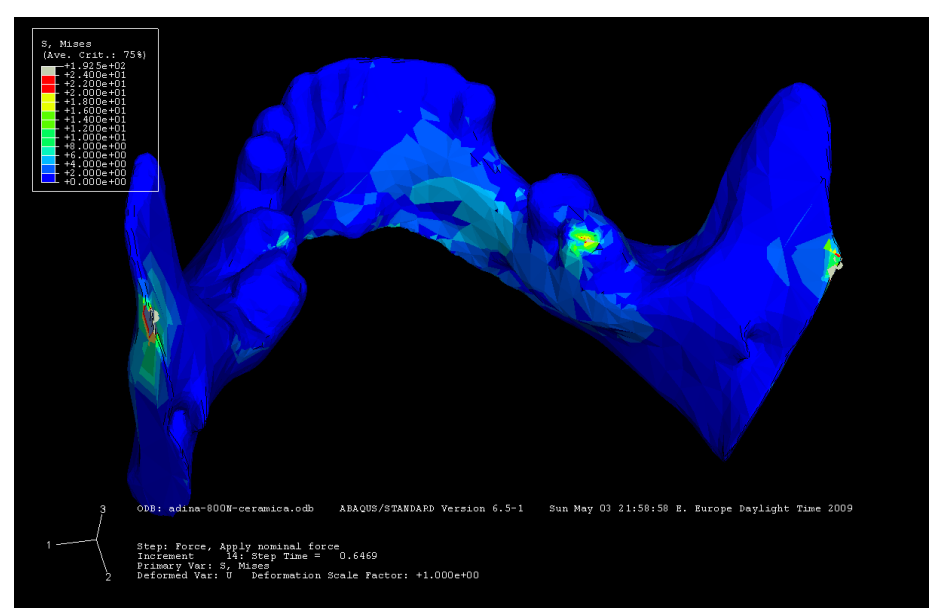

Figure 5. Ceramic molar Von Misses tension for a $500 \mathrm{~N}$ load 
Figure 6 reveal that under overload conditions (a force of $800 \mathrm{~N}$ ), the tension developed at the level of the spines varies between $243.5 \mathrm{MPa}-240 \mathrm{MPa}$, but is associated with an increased demand for the cervical area, (a tension of $60 \mathrm{MPa}$ ), as well as both slopes of the edentulous ridge (a voltage of 140 $\mathrm{MPa})$.

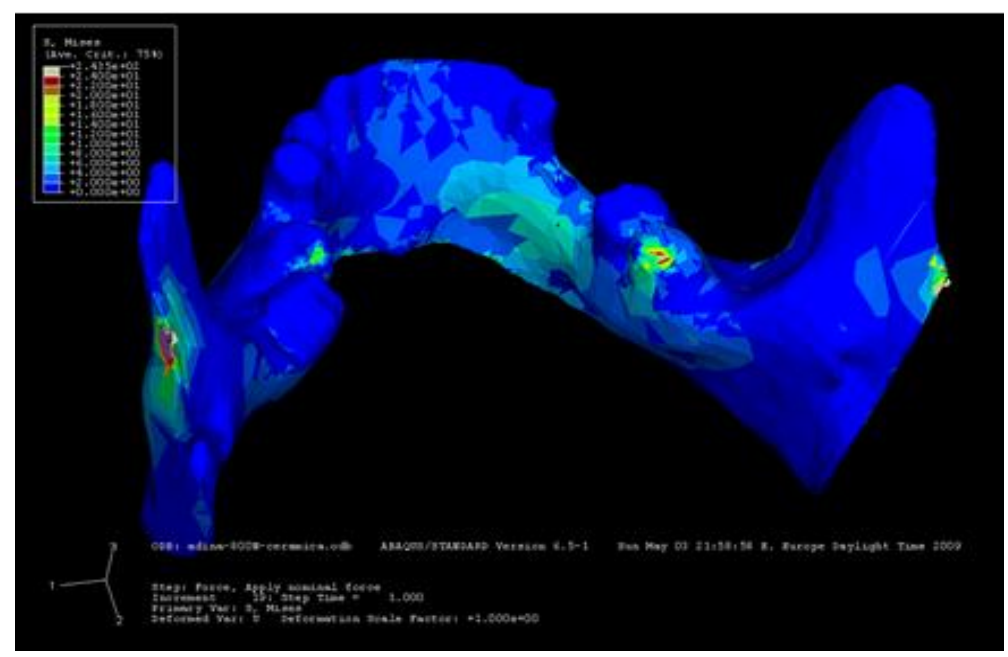

Figure 6. Von Misses stress at the molar level restored ceramic, at a request of $800 \mathrm{~N}$

In the occlusion, the state of pressures and stresses at the level of the two structures in direct contact is clearly observed.

At a force of approximately $300 \mathrm{~N}$ developed during the exercise of the functions of the stomatognathic system, it is found that the most affected areas are located at the level of the occlusal contact area in the vestibular half (the tip of the vestibular cusps), where theses up to $180 \mathrm{MPa}$ are recorded, gradually decreasing to $160 \mathrm{MPa}$ towards the root and bone portion (Figure 7).

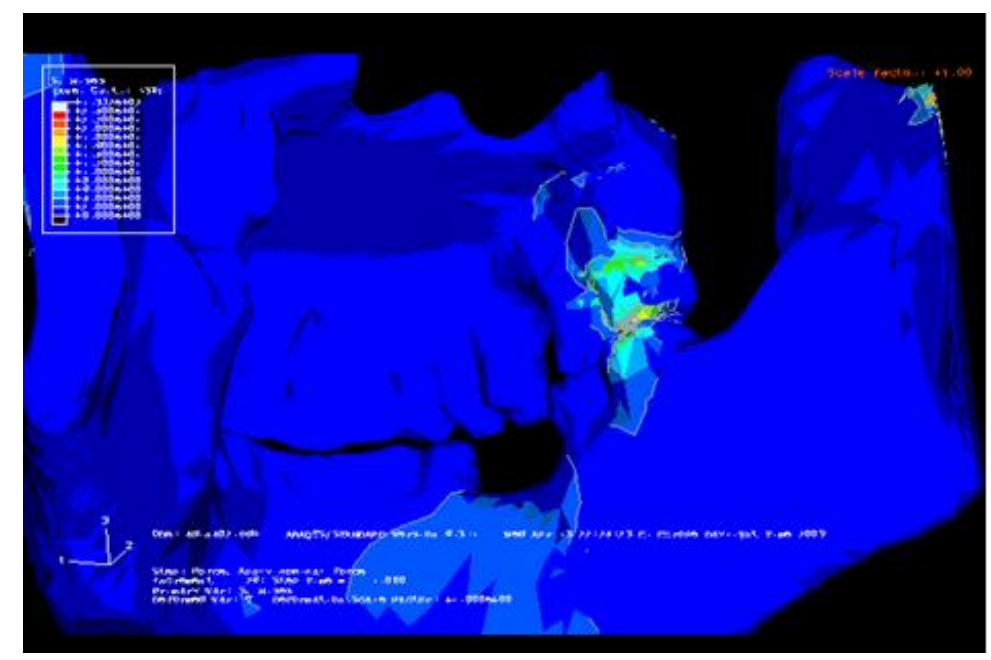

Figure 7. Odonto-periodontal changes at $300 \mathrm{~N}$ requests

At a force of $500 \mathrm{~N}$, at the level of the restored ceramic molar, it develops at interface level restoration - tooth, voltages of $160 \mathrm{MPa}$, the same value being recorded at the level of both sides of the edentulous ridge (Figure 8). 


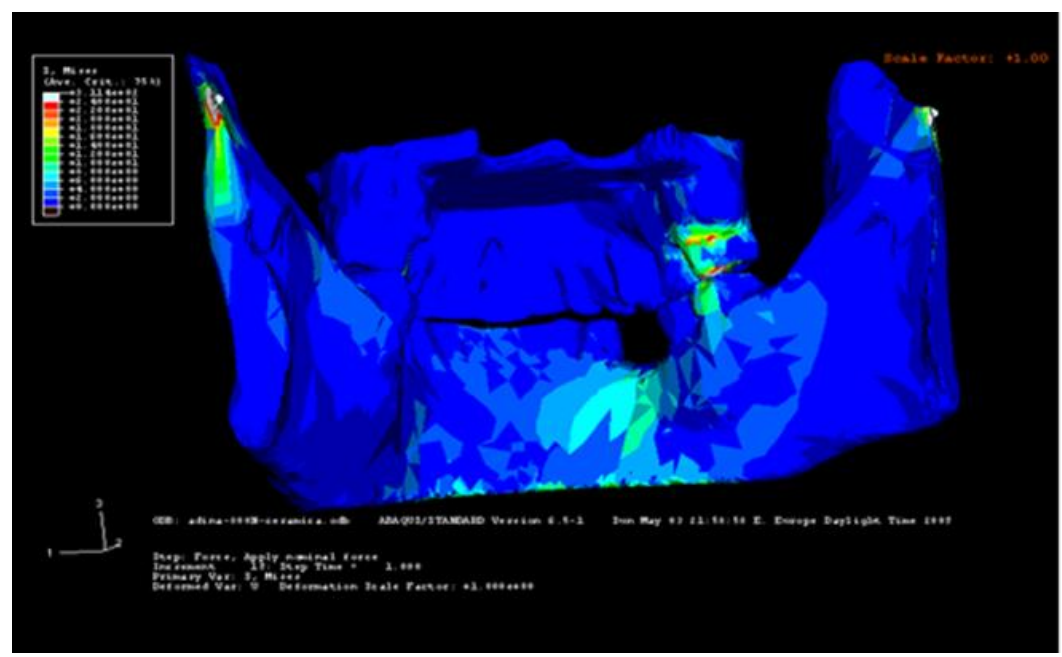

Figure 8. Von Misses stress at the molar levelrestored ceramic, at a request of $500 \mathrm{~N}$

At an overload of $800 \mathrm{~N}$, all structures are affected: the entire area of occlusal contact, the cervical regions, antagonistic teeth, with the transmission of the request to the bone bed of the edentulous region. Tension reach values of $310 \mathrm{MPa}$, in the area of maximum overload (Figure 9).

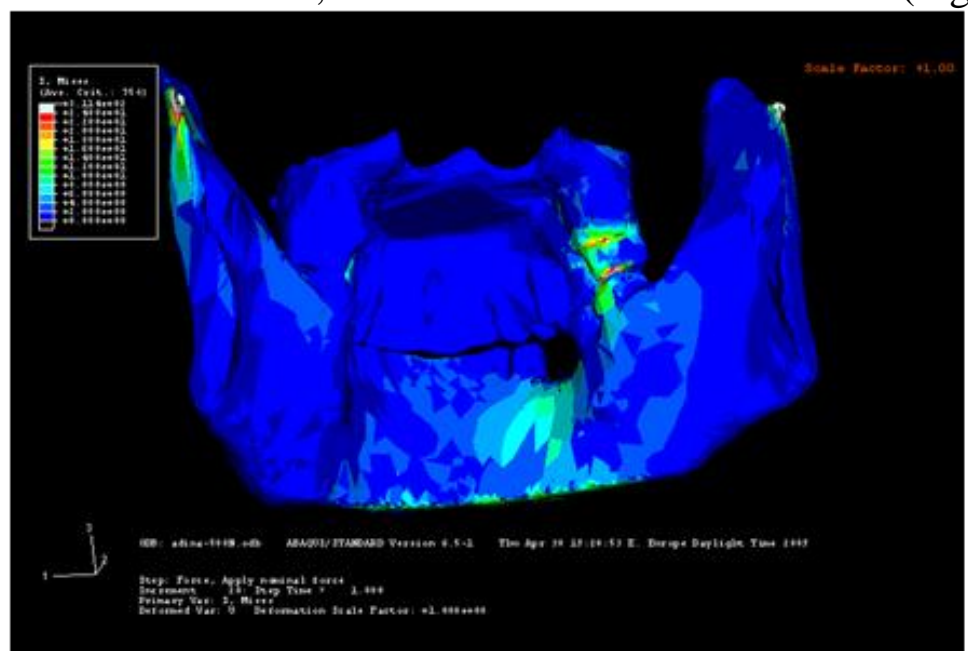

Figure 9. Von Misses stress at the molar level restored ceramic, at a request of $800 \mathrm{~N}$

During an occlusal stress, the tip of the cusp is subjected to axial compressive loading, which induces a state of cervical tension associated with the occurrence of a shear stress acting at right angles to the load.

Ceramic dental restorations determine the occurrence of stress concentrators at the dentin-crown interface, the greater the value and the area of action the greater the modulus of elasticity of the material from which the crown is made.

It is known that von Misses stress will always follow the path of the harder material, with a higher modulus of elasticity. In our case, the harder material is ceramic, and the occlusal load will be transmitted to the underlying dental tissues, the load being dissipated down to the root, radial and apical, which explains, moreover, the degree of damage of the affected tooth [4-9].

The tension concentrators at the level of the restored tooth are attenuated, which is perfectly logical, since most of the tension in this region is taken over by the naturally antagonistic tooth. This confirms the high degree of wear on the tooth that is in direct contact with the restoration $[1,4]$. 
In any case, we can say that, in all situations, a sum of stresses acts, expression of the combination of normal (traction-compression, crushing, bending) and tangential (shear, or torsion) stresses, which will result in the initiation and / or and the evolution over time of combined wear patterns, that of abrasion, intermingling with the fatigue of stress as the intensity of the applied force increases $[8,10]$.

\section{Conclusions}

Given the results of the current study, further investigations are warranted. Within the limitations of this study it was concluded that: understanding the properties of the dental material allows foreshadowing of the strain zones and thus the appearance of the first wear areas located either on dental support or on the restorative material; the most burdened areas are represented by cusps that come in contact and these areas are oriented along the direction of the masticating muscles. The geometry of this burdened area is adapted to the effort that it must endure, being the most developed one of the studied area. In all cases a sum of tensions act, as an expression of combined normal tensions (tensile, compressive, crushing, bending) and tangential (shear or torsion), which will result in the initiation and / or evolution of combined patterns of wear, abrasive wear braiding with fatigue as the intensity of the applied force increases.

\section{References}

1. HEINTZE SD, CAVALLERI A, FORJANIC M, ZELLWEGER G, ROUSSON V. Wear of ceramic and antagonist-a systematic evaluation of influencing factors in vitro. Dent Mater 2008;24:433-449

2. KIM MJ, OH SH, KIM JH, JU SW, SEO DG, JUN SH, AHN JS, RYU JJ. Wear evaluation of the human enamel opposing different Y-TZP dental ceramics and other porcelains. J Dent 2012;40:979988

3. LAMBRECHTS P, DEBELS E, VAN LANDUYT K, PEUMANS M, VAN MEERBEEK B. How to simulate wear? Overview of existing methods. Dent Mater 2006;22:693-701.

4. MITOV, G., HEINTZE, S.D., WALZ, S., WOLL, K., MUECKLICH, F., POSPIECH, P. Wear behavior of dental Y-TZP ceramic against natural enamel after different finishing procedures. Dent. Mater. 2012, 28, 909-918.

5. NAUMOVA ELLA A., SCHNEIDER STEPHAN, ARNOLD WOLFGANG, PIWOWARCZYK ANDREE. Wear Behavior of Ceramic CAD/CAM Crowns and Natural Antagonists. Materials 2017, $10,244$.

6. REKOW, D.; THOMPSON, V.P. Near-surface damage-A persistent problem in crowns obtained by computer-aided design and manufacturing. Proc. Inst. Mech. Eng. Part H 2005, 219, 233-243.

7. RUI TAO PENG, FANG LU, XIN ZI TANG, YUAN QIANG TAN. DEM Simulation of Ceramic Tool Abrasion in Machining Superalloy. Materials Science Forum, Vols. 800-801, pp. 385-389, 2014

8. SAIKI, O., KOIZUMI, H., AKAZAWA, N., KODAIRA, A., OKAMURA, K., MATSUMURA, H. Wear characteristics of polished and glazed lithium disilicate ceramics opposed to three ceramic materials. J. Oral Sci. 2016, 58, 117-123.

9. YONG-SEOK JANG, THUY-DUONG THI NGUYEN ET ALL. In vitro wear behavior between enamel cusp and three aesthetic restorative materials: Zirconia, porcelain, and composite resin. J Adv Prosthodont. 2019 Feb;11(1):7-15

10. ZESEWITZ, T.F., KNAUBER, A.W., NORTHDURFT, F.P. Fracture resistance of a selection of full-contour all-ceramic crowns: An in vitro study. Int. J. Prosthodont. 2014, 27, 264-266.

$\overline{\text { Manuscript received: } 18.09 .2029}$ 